Date: Dec. 26, 2014

\title{
Pluggable microbial fuel cell stacks for septic wastewater treatment and electricity production
}

\author{
Hadi Yazdi ${ }^{\dagger}$, Liliana Alzate-Gaviria ${ }^{\ddagger}$ Zhiyong Jason Ren ${ }^{\dagger *}$ \\ ${ }^{\dagger}$ Department of Civil, Environmental, and Architectural Engineering, University of Colorado \\ Boulder, Boulder, CO, USA \\ ${ }^{\ddagger}$ Renewable Energy Unit, Yucatan Center for Scientific Research (CICY), Yucatán, Mexico
}

*Corresponding author Ren E-mail: jason.ren@ colorado.edu; phone: (303) 492-4137; fax: (303) 492-

7317 


\begin{abstract}
Septic tanks and other decentralized wastewater treatment systems play an important role in protecting public health and water resource for remote or developing communities. Current septic systems do not have energy production capability, yet such feature can be very valuable for areas lack access to electricity. Here we present an easy-to-operate microbial fuel cell (MFC) stack that consists a common base and multiple pluggable units, which can be connected in either series or parallel for electricity generation during waste treatment in septic tanks. Lab studies showed such easy configuration obtained a power density of $142 \pm 6.71 \mathrm{~mW} \cdot \mathrm{m}^{-2}$ when 3 units are connected in parallel, and preliminary calculation indicates that a system that costs approximately US \$25 can power a 6-watt LED light for 4 hours per day with great improvement potential. Detailed electrochemical characterizations provide insights on system internal loss and technology advancement needed.
\end{abstract}

Keywords: septic system, decentralized wastewater treatment, microbial fuel cell 


\section{Introduction}

Traditional decentralized wastewater treatment systems (DWATS) such as septic tanks and pour flush latrines are cost-effective and low-maintenance ways to protect public health and water resource. In the US, approximately $20 \%$ of all homes or 20 million people use septic tanks for the primary wastewater treatment (Zamalloa et al., 2013). In developing countries, billions of people rely on DWATS to provide basic sanitation and protect public health. The wastewater stored in DWATS contain high strength organics, up to $1.47 \times 10^{7}{\mathrm{~J} . \mathrm{kg}^{-1} \mathrm{COD}}$ (Shizas and Bagley, 2004), which can be potentially converted to usable energy for onsite use. Such local and renewable energy source can be especially valuable to households that are lack access to electricity.

Microbial fuel cells (MFCs) are an emerging technology that produces direct electricity from wastewater using exoelectrogentic microorganisms. (Wang and Ren, 2013; Logan and Rabaey, 2012; Li et al., 2014). The performance of MFCs has increased dramatically in the past decade, but many MFC studies for wastewater application focused on replacing big aeration tanks to save energy in centralized treatment plants, yet few work has looked at converting DWATS to energy neutral or energy positive systems. Current development of large scale MFC systems for centralized utilities is facing challenges on reactor configurations and cathode systems (Li et al., 2014; Wang et al., 2013). While using liquid catholyte is not feasible for such applications, air-cathode using free $\mathrm{O}_{2}$ as the electron acceptor has been considered more sustainable. However, the structure of air cathode has been complicated, the cost has been high, and the power output remains low compared with other type of cathodes (Zhuang et al., 2012; Forrestal et al., 2014; Zhang et al., 2010). Stacks of MFC units are generally needed to provide applicable voltage or current for direct utilizations, and they can be either connected in parallel or series. However, the power output 
of the whole system can be significantly affected by one or a few low-performing units, a phenomenon called voltage reversal (Wang et al., 2012; Kim et al., 2011). When one unit gone bad, it is hard to take the unit offline due to the interconnection of the many cells, and it becomes a maintenance headache. While the MFC technology holds great potential for converting DWATS to energy generating systems, these challenges make the development and deployment of MFC systems in developing countries extremely difficult, because for such applications the cost has to drop dramatically (to approximately $\$ 20$ dollar per unit), the system has to be simple and easy to operate (for non-educated users), and the materials and replacement parts have to be locally available for easy replacement. All these factors are deemed critical during our field studies in Uganda through the Gates Foundation Reinvent the Toilet Grand Challenge program.

In this study, we present an easy pluggable MFC stack for decentralized wastewater treatment and electricity production. Individual column MFC units are connected using a common base and the compact MFC stack float in septic or holding tanks to convert organic waste to electricity. If one unit is broken, it can be easily taken offline for repair, or a new unit can be plugged in as easy replacement, so the whole system won't be compromised. The units can be made available in local hardware stores for easy repair or replacement. We tested performance of a 3-unit prototype system in terms of organic removal and energy production, and we conducted electrochemical characterizations and basic cost analysis to understand the advantages and challenges associated with the design.

\section{Materials and Methods}

\subsection{MFC stack design and construction}


Column air-cathode MFC units without metal catalysts were built by wrapping an assembly of anode, separator, and cathode layers around a perforated PVC plastic tube (L $19 \mathrm{~cm}$ x D $3.5 \mathrm{~cm}$ ), with the anode facing outside exposed to the liquid, and the cathode layer facing inside exposed to air (Lu et al., 2014). Activated carbon cloth (ACC, Zorflex®, Chemviron, UK) was used as the anode, and the air-cathode was constructed according to Zhang et al, (2010) and Lu et al, (2014) by applying 3 layers of polymethylsiloxane (PDMS, Dow Corning $^{\circledR}$, MI) diffusion layers on activated carbon cloth but without Pt catalysts. Three layers of J-cloth (DuPont ${ }^{\mathrm{TM}}$ Sontara $^{\circledR}$, style 8864 ) were used as the separator between the two electrodes (Zhang et al., 2009; Haeger et al., 2014). Three column MFC units were then screwed into a common PVC T-connector base, in which passive air circulation can be conducted through the units (Figure 1). The MFC stack was placed into a 3 L container with synthetic wastewater to simulate DWATS conditions.

\subsection{Reactor inoculation and operation}

The reactor was inoculated with anaerobic sludge from the Boulder Water Resource Recovery Plant, and the volume ratio between the sludge and the media was 1:9. The medium with $50 \mathrm{mM}$ phosphate buffer solution (PBS) contained (per liter) $1.6 \mathrm{~g}$ $\mathrm{NaCH}_{3} \mathrm{COO}, 0.13 \mathrm{~g} \mathrm{KCL}, 0.31 \mathrm{~g} \mathrm{NH}_{4} \mathrm{CL} ; 5.84 \mathrm{~g} \mathrm{NaH}_{2} \mathrm{PO}_{4} . \mathrm{H}_{2} \mathrm{O}, 15.5 \mathrm{~g} \mathrm{Na}_{2} \mathrm{HPO}_{4} .5 \mathrm{H}_{2} \mathrm{O}$, and trace minerals and vitamins (Luo et al., 2012b; Forrestal et al, 2012). The MFC units were operated separately under $100 \Omega$ resistance in a common container without connecting to each other, and when 3 repeatable voltage generation cycles were obtained, the 3 MFC units (1, 2 and 3) were connected in series or parallel and operated for another 3 months. All operations were conducted in fed-batch mode in room temperature $\left(22 \pm 2^{\circ} \mathrm{C}\right)$, and the media solution was replaced when MFC voltage dropped below $0.20 \mathrm{~V}$. (Huggins et al., 2014). 


\subsection{Analysis}

The voltage $\mathrm{V}(\mathrm{V})$ crosses the external resistor was measured every 10 min using a data acquisition system (Keithley, OH), and the current (A) was determined according to Ohm's law, $\mathrm{I}=\mathrm{V} / \mathrm{R}$. To measure the internal resistance, the MFC units were connected to a Gamry Potentiostat in a two-electrode mode, with the anode serving as the working electrode and cathode acting as both reference and counter electrode (Luo et al., 2012b). Due to the very tight space between the electrodes, it was not possible to use 3-electrode system. The electrochemical impedance spectra (EIS) measurements were performed by using an interface instrument Gamry (Interface PC4.3000 ${ }^{\mathrm{TM}}$, NJ, USA), after the reactor was operated under open circuit conditions for $1.5 \mathrm{~h}$. The impedance spectra were recorded in the frequency range from 0.01 to $100,000 \mathrm{~Hz}$ by applying a sinusoidal excitation signal of $0.10 \mathrm{~V}$ (Luo et al., 2012b). The data were fitted to an equivalent electrical circuit by using the Ec$\mathrm{Lab}^{\circledR}$ (version 10.37) impedance analysis software (Ramasamy et al., 2008). Chemical oxygen demand (COD) was measured using standard method colorimetric (Method 5220, HACH Co., CO). Columbic efficiency was calculated as the ratio of total coulombs transferred to each circuit from the substrate to the maximum possible coulombs if all substrate removal produced current.

\section{Results and discussion}

\subsection{Performance of individual MFC units}

The voltage profiles of the 3 individual column MFCs are shown in Figure 2. While for each MFC, the consecutive batches show stable voltage output, the voltage production among the 3 MFCs varied. MFC 2 produced the highest output with a stable voltage of $0.23 \mathrm{~V}$ under a $100 \Omega$ external resistance, and each batch sustained for 4-5 days. Power density curves 
shown in Figure 3B indicate that the maximum power output was $158 \pm 10.01 \mathrm{~mW} . \mathrm{m}^{-2}$ (MFC 2). In comparison, the power outputs from MFC 1 and MFC 3 were lower. The maximum power output from MFC 1 and MFC 3 was $80 \pm 6.23 \mathrm{~mW} \cdot \mathrm{m}^{-2}$ and $126 \pm 2.42 \mathrm{~mW} \cdot \mathrm{m}^{-2}$, respectively. Because the 3 column MFCs used the same inoculum and shared the same anolyte solution and were exposed to the same air flow, the performance differences are believed due to electrode variances during manufacturing process, such as uneven application of the cathode diffusion layer caused inefficient mass transfer. Due to the tight sandwich type of structure, it was not possible to test individual cathode potentials. Such variability among different units within one MFC stack has been reported previously (Zhuang et al., 2012), and it can be addressed through standardized production. The power output from these reactors were comparable with previous studies using similar electrodes, separators, and media, where the power densities ranged from $52-170 \mathrm{~mW} . \mathrm{m}^{-2}$ (Janicek et al., 2014; Sevda et al., 2013; Kumar et al., 2013). One advantage of the column MFCs in this study is that it eliminated the use of expensive Pt catalysts, which does compromise the power output compared with Ptcathodes, but more importantly, it significantly reduced the cost of the system, making it more feasible for developing country applications. The COD removal was $94.5 \pm 2.67 \%$ in the common container, and the Columbic efficiency for MFC2, MFC3, and MFC1 was 35.6\%, $20.1 \%$, and $17.3 \%$, respectively.

\subsection{MFC stack connected in parallel or series}

When the 3 units were connected in parallel or in series, the current or voltage, as well as the power output was hypothesized to increase, so the overall system can provide higher energy. For repeatable cycles shown in Figure 2, the parallel connection under $100 \Omega$ resulted in a $40 \%$ increase in voltage $(0.32 \mathrm{~V})$ compared with the best performing MFC 2 , while the 
voltage output in series was only comparable to MFC $2(0.23 \mathrm{~V})$ (Figure 2), which is a similar trend observed by Zhuang et al (2012). The low output from serial connections is mainly due to the observed voltage reversal during operation, which has been reported as a common problem associated in MFC stacks by previous studies (Kim, et al., 2012). The polarization curves (Figure 3A) show that the 3 individual cells show nearly identical open circuit voltages (OCV), but MFC 1 shows much lower current than MFC 2 and 3 and therefore lower power density (Figure 3B). This confirms that MFC 1 limited the overall performance of the system when connected in series. Several methods have been reported effective to reduce or prevent voltage reversal through circuitry or energy harvesting, so this study did not focus on this topic (Kim, et al., 2012; Wang, et al., 2012). A much higher OCV of 1.10V was obtained when the 3 units are connected in series, while a similar OCV $(0.57 \mathrm{~V})$ to individual cells was obtained when they are connected in parallel, which agrees with hypothesis how different connections affect stack power output. In terms of power density, when the units are collected in series, the maximum power density of $97.5 \pm 7.5 \mathrm{~mW} . \mathrm{m}^{-2}$ was obtained, and this number was increased to $142 \pm 6.7 \mathrm{~mW} \cdot \mathrm{m}^{-2}$ when they were connected in parallel, primarily due to the increased current (Figure 3B). The parallel connection showed similar power output compared with the best performing MFC 2, but the absolute current output (4.85 mA) at the peak power was 2.6 fold higher than the individual MFC 2 (1.86 $\mathrm{mA}$ ). In addition to voltage reversal, the different power outputs from individual units and stacked configurations could be partially explained by the different internal resistances, which will be discussed in detail in the next section. Overall, the parallel connection showed the lowest internal resistance $(395 \pm 1.16 \Omega)$, which as $27 \%$ lower than the series connection (Table 1). The parallel connection allows increased surface area for electron flow and therefore potentially reduces electrode over potential (Zhuang et al., 2012). Each fed-batch 
cycle typically lasted around 4-5 days, and the COD removals in parallel connection and serial connection were $95 \%$ and $87.5 \%$, respectively, resulting in the columbic efficiencies $22 \%$ and $8 \%$, respectively.

\subsection{System electrochemical characterization}

The experimental data were fitted using $\mathrm{Ec}^{-L a b}{ }^{\circledR}$ software (version 10.37) by $\chi 2$ minimization, obtaining values between $10^{-1}-10^{-2}$. The equivalent circuit of the whole MFC contemplates the ohmic resistance, the charge transfer process and the double layer on the electrode, as well as diffusion and transfer processes. The constant phase element (CPE) is attributed to the heterogeneity of either the electrode or the reactions. The controlled diffusion (G-Gerischer) element corresponds to proton transfer processes $\left(R_{d}\right)$. The experimental finding shows that Gerischer phase element could be used to fit the low frequency semicircle in the impedance diagram (Meland et al., 2005), while Gerischer element was used to fit the impedance of the electrodes involved in diffusion (Baranitharan et al., 2014).

Figure 4 shows that the Nyquist plots at very high frequency (f $>20 \mathrm{kHz}$ ) describes mainly the impedance at anode process, and when $\mathrm{f}<20 \mathrm{kHz}$, the plots are influenced by the cathode processes of oxygen reduction. The high-medium frequency semicircle, weakly separable and visible (as nearly linear part in Z, Zplot), characterizes the charge transfer and mass transfer steps. Taking into account the noticeable influence of cathode process also on the low-frequency $(1 \mathrm{~Hz}$ ), the diffusion step is clearly more important (Kivi et al., 2012). The detailed characterization of internal resistances $\left(R_{\text {in }}\right)$ using EIS reveals their correlation with the reactor performance (Luo et al., 2012b; Ren et al., 2011). The resistance was characterized as ohmic resistance $\left(\mathrm{R}_{\mathrm{ohm}}\right)$, charge-transfer resistance $\left(\mathrm{R}_{\mathrm{ct}}\right)$ and diffusion 
resistance $\left(R_{d}\right)$. Table 1 shows the internal resistance of MFC 1, 2 and 3 was $849 \pm 1.32 \Omega$, $200 \pm 0.70 \Omega$, and $460 \pm 1.02 \Omega$, respectively, which negatively correlated with their voltage outputs and power densities shown in Figure 2 and 3. Such relationship can also be found in the parallel and serial connections, because the parallel connection has a lower $R_{\text {in }}(395 \pm 1.16$ $\Omega)$ than the serial connection $(545 \pm 1.51 \Omega)$. Likewise, CPE values for parallel and series were $2.41 \mathrm{E}-03 \Omega^{-1} \mathrm{~s}^{\alpha}$ and $4.49 \mathrm{E}-04 \Omega^{-1} \mathrm{~s}^{\alpha}$, with $\alpha \approx 0.8$ respectively. CPE is considered a nonideal capacitor in both systems. On comparing the capacitance values $(\mathrm{Cdl})$ between parallel (5.99E-04 F) and series (9.44 E-05 F) connections, we found that parallel connection significantly decreased the $\mathrm{R}_{\mathrm{int}}$ and resulted in higher output (Ren et al. 2014), and its capacitance was $80 \%$ higher due to facilitated charge accumulation on the electrode interface. (Marcus et al., 2007).

The $\mathrm{R}_{\mathrm{ohm}}$ accounts a small fraction of the total $\mathrm{R}_{\mathrm{int}}$, with the $\mathrm{R}_{\mathrm{ohm}}$ of MFC 1,2 and 3 only represents $1.5 \%, 4.5 \%$, and $2.2 \%$ of the $\mathrm{R}_{\text {int }}$ of each unit, respectively. In comparison, the $\mathrm{R}_{\mathrm{ct}}$ accounts a higher percentage, mainly because no metal catalysts were used in the MFCs, and the oxygen reduction on the cathode is considered the rate limiting process. Table 1 shows that MFC $2(88.63 \pm 1.45 \Omega)$ has much lower $R_{\mathrm{ct}}$ compared with MFC 1 and $3(195.90 \pm 15.04$ $\Omega$ and $150.30 \pm 19.55 \Omega$, respectively), indicating a faster charge transfer in MFC 2 (Srikanth et al., 2008). By applying a new rolling-press method for the air cathode, the $\mathrm{R}_{\mathrm{ct}}$ can be significantly reduced and cathode performance can be improved (Zhang et al, 2014). Compared with $R_{\mathrm{ohm}}$ and $\mathrm{R}_{\mathrm{ct}}$, the largest fraction of $\mathrm{R}_{\mathrm{in}}$ comes from $\mathrm{R}_{\mathrm{d}}$, and the values $\mathrm{R}_{\mathrm{d}}$ for MFC 1, 2 and 3 were $644.70 \pm 31.89$ (75.9\%), 102.61 $\pm 8.66(51.2 \%)$ and $299.47 \pm 14.59$ $(65.1 \%)$ (Table 1). This indicates the ion transfer, mainly the relatively slow kinetics on oxygen reduction and transfer on the air-cathode is the rate limiting process. While the 
avoidance of using metal-free catalyst on the cathode reduces the reactor cost, this slow kinetics needs to be improved. Biofouling or scaling maybe another reaction of increased $R_{d}$, as Tugtas et al., (2011) found that the development of biofilm on air cathode and accumulation of inert materials may create a barrier to oxygen reduction. In addition, the pervious pipe structure can be further optimized to improve air diffusion into the cathode (Janicek et al., 2014).

\subsection{Economic considerations}

Simple configuration and low cost are key factors for the successful application of MFC in real world. This study attempts to build simple and easy-to-operate MFC units with acceptable power outputs, so with further development they can be used in households in remote or developing communities. The three main materials used in the study are activated carbon cloth $\left(\right.$ Zorflex $^{\circledR}$ ) without any metal catalyst, wipe J-cloth Sontara ${ }^{\circledR} 8864$, and very small amount of PDMS (Dow Corning ${ }^{\circledR}, \mathrm{MI}$ ) as a binder. Based on current prices from online vendors (ww.alibaba.com; www. vwr.com) and personal communications with retailers, the costs of these materials are US $\$ 5 \mathrm{~m}^{-2}$ (activated carbon cloth), $\$ 0.31 \mathrm{~m}^{-2}$ (wipe J-cloth) and $\$ 0.28 \mathrm{~m}^{-2}$ (PDMS), respectively. For each $\mathrm{m}^{2}$ material used in pluggable MFC stack is approximately $\$ 6.07 \mathrm{~m}^{-2}$ using current manufacturing method. For a septic tank serving a household of 4-5 with wastewater amount of $90 \mathrm{~L} /$ person/day, to remove $80 \%$ of COD in 3-4 days, the septic tank may have a volume of $2 \mathrm{~m}^{3}$ (500 gallon), consisting one or two chambers. Take a two chamber design as an example, the first chamber is designed for solid precipitation while keeping the scum afloat, while the MFC stacks can be installed in the second chamber, and the surface area is calculated to be $4.2 \mathrm{~m}^{2}$, costing US $\$ 25$ based on US market price and current configuration, which is orders of magnitudes lower than previous 
stack designs (Wang and Ren, 2013). The cost can be even lower when using developing country locally available materials such as biochar electrodes and plastic mesh separators.

The current MFC stacks showed moderate power output due to the use of low cost materials and not yet optimized design. Based on the top power output obtained from this study, the MFC stacks with $4.2 \mathrm{~m}^{2}$ surface area can get an electricity output of approximately 24 wh.d ${ }^{-1}$, enough to power a 6 watt LED light bulb for 4 hours per day. Many improvements can be made to increase the power output, such as packing more materials to increase surface area per volume, optimizing reactor configuration to reduce internal resistance, applying efficient energy harvesting technology, and certainly developing better performing materials. These considerations will be incorporated into further studies, and we do anticipate that a sustainable 100 wh. $\mathrm{d}^{-1}$ can be accomplished within the near future.

\section{Conclusions}

The easily pluggable and low cost microbial fuel cell design provides a simple solution for concurrent waste treatment and electricity generation in decentralized wastewater treatment systems. Through the characterization of individual and stack MFCs, parallel connection of multiple units showed higher energy output without voltage reversal problem. Detailed electrochemical characterization revealed the internal resistance distribution and provides insights on further system improvement. With further technology advancement, such systems can be suitable waste-to-energy units for remote or developing communities.

\section{Acknowledgements}


Yazdi and Ren were supported by the Bill \& Melinda Gates Foundation's Grand Challenges

Explorations Grant OPP1043362. Alzate-Gaviria was supported by CONACYT through the sabbatical grant 204007. The authors thank Francisco del Rio, Gerardo Camara and Jorge Dominguez for support of 3D graph and software license.

\section{References}

1. Baranitharan, E., Khan, M., Prasad, D., Teo, W., Tan, G., Jose, R. 2014. Effect of biofilm formation on the performance of microbial fuel cell for the treatment of palm oil mill effluent. Bioprocess Biosyst. Eng. 10.1007.s00449-014-29-9.

2. Forrestal, C., Xu, P., Jenkins, PE., Ren, ZJ. 2012. Microbial desalination cell with capacitive adsorption for ion migration control. Bioresour. Technol. 120, 332-336.

3. Forrestal, C., Huang, Z., Ren, ZJ. 2014. Percarbonate as a Naturally Buffering Catholyte for Microbial Fuel Cells. Bioresour. Technol. 172, 429-432.

4. Haeger, A., Forrestal, C., Xu, P., Ren, ZJ. 2014. High Performance Spiral Wound Microbial Fuel Cell with Hydraulic Characterization, Bioresour. Technol. 174, 287293.

5. Huggins, T., Wang, H., Kearns, J., Jenkins, P., Ren, ZJ. 2014. Biochar as a sustainable electrode material for electricity production in microbial fuel cells. Bioresour. Technol., 157, 114-119.

6. Janicek, A., Fan, Y., Liu, H. 2014. Design of microbial fuel cells for practical application: a review and analysis of scale-up studies. Biofuels 5, 79-92.

7. Kim, Y., Hatzell, MC, Hutchinson, AJ., Logan, BE. 2011. Capturing power at higher voltages from arrays of microbial fuel cells without voltage reversal. Energy Environ. Sci. 4, 4662-4667

8. Kivi, I., Anderson, E., Moller, P., Nurk, G., Lust, E. 2012. Influence of Microstructural Parameters of LSC Cathodes on the Oxygen Reduction Reaction Parameters. J. Electrochem. Soc.. 159, 743-750.

9. Kumar, G., Sarathi, V., Nahm, K. 2013. Recent advances and challenges in the anode architecture and their modifications for the applications of microbial fuel cells. Biosens.Bioelectron. 43, 461-475. 
10. Li, W.-W., Yu, H.-Q., He, Z. 2014. Towards sustainable wastewater treatment by using microbial fuel cells-centered technologies. Energy Environ. Sci. 7 (3), 911-924.

11. Lu, L., Yazdi H., Jin, S., Zuo, Y. Fallgren, P. H., Ren, Z. J. 2014. Enhanced bioredmediation of hydrocarbon-contaminated soil using pilot-scale bioelectrochemical systems. J. hazardous materials, 274, 8-15.

12. Luo, H., Xu, P., Jenkins, P., Ren, Z. 2012a. Ionic composition and transport mechanisms in microbial desalination cells. J. Membrane Sci 409-410, 16-23.

13. Luo, H., Xu, P., Ren, Z. 2012b. Long-term performance and characterization of microbial desalination cells in treating domestic wastewater. Bioresour. Technol. 120, $187-193$.

14. Logan, B.E., Rabaey, K. 2012. Conversion of wastes into bioelectricity and chemicals using microbial electrochemical technologies, Science 337,686-690.

15. Marcus, A., Torres, T., Rittmann, B. 2007. Conduction-Based Modeling of the Biofilm Anode of a Microbial Fuel Cell. Biotechnol Bioeng 98, 1171-32.

16. Meland, A., Bedeaux, D., Kjelstrup, S. 2005. A Gerischer Phase Element in the Impedance Diagram of the Polymer Electrolyte Membrane Fuel Cell Anode. J. Phys. Chem. B. 109, 21380-21388.

17. Ramasamy, RP., Ren, Z., Mench, MM., Regan, JM. 2008. Impact of initial biofilm growth on the anode impedance of microbial fuel cells. Biotechnol. Bioeng. 101(1), $101-108$.

18. Ren, L., Ahn, Y., Hou, H., Zhang, F., Logan, B. 2014. Electrochemical study of multi-electrode microbial fuel cells under fed-batch and continuous flow conditions. J. Power Sources 257, 454-460.

19. Ren, Z., Yan, H., Wang, W., Mench, M., Regan, J. 2011. Characterization of Microbial Fuel Cells at Microbially and Electrochemically Meaningful Time scales. Environ. Sci. Technol. 45, 2435-2441.

20. Sevda, S., Dominguez-Benetton, X., Vanbroekhoven, K., Sreekrishnan, T., Pant, D. 2013. Characterization and comparison of the performance of two different separator types in air-cathode microbial fuel cell treating synthetic wastewater. Chem. Eng. J. $228,1-11$.

21. Shizas, Bagley D.M. 2004. Experimental determination of energy content of unknown organics in municipal watewater streams. J.Energy Engin., 130, 45-55.

22. Srikanth, S., Marsili, E., Flickinger, M., Bond, D. 2008. Electrochemical characterization of Geobacter sulfurreducens cells immobilized on graphite paper electrodes. Biotechnol. Bioeng. 99, 1065-1073. 
23. Tugtas, A., Cavdar, P., Calli, B. 2011. Continuous flow membrane-less air cathode microbial fuel cell with spunbonded olefin diffusion layer. Bioresour. Technol. 102, 10425-10430.

24. Wang H, Ren Z.J. 2013. A comprehensive review of microbial electrochemical systems as a platform technology. Biotechnol. Adv. 31, 1796-1807.

25. Wang, H., Park, JD., Ren, Z. 2012. Active energy harvesting from microbial fuel cells at the maximum power point without using resistors. Environ. Sci. Technol., 46 (9), 5247-5252.

26. Zamalloa, C., Arends, J., Boon, N., Verstraete, W. 2013. Performance of a lab-scale bio-electrochemical assisted septic tank for the anaerobic treatment of black water. New. Biotechnol. 30, 573-580.

27. Zhang, F., Saito, T., Cheng, S., Hickner, M., Logan, B. 2010. Microbial fuel cell cathodes with poly (dimethylsiloxane) diffusion layers constructed around stainless steel mesh current collectors. Environ. Sci. Technol. 44, 1490-1495.

28. Zhang, X., Cheng, S., Wang, X., Huang, X., Logan, B. 2009. Separator characteristics for increasing performance of microbial fuel cells. Environ. Sci. Technol. 43, 84568461.

29. Zhang,Y., Wang, X., Li, X., Gao, N., Wan, L., Feng, C., Zhou, Q. 2014. A novel and high performance activated carbon air-cathode with decreased volume density and catalyst layer invasion for microbial fuel cell. RSC Adv. 4, 42577-42580

30. Zhuang, L., Zheng, Y., Zhou, S., Yuan, Y., Yuan, H., Chen, Y. 2012. Scalable microbial fuel cell (MFC) stack for continuous real wastewater treatment. Bioresour. Technol. 106, 82-88. 


\section{Table Caption}

Table 1. Summary of the open circuit voltage, power density and equivalent circuit fit of experimental results for individual and stack MFC units.

\section{Figure Caption}

Figure 1. Schematic design of and detailed structure of the pluggable microbial fuel cell stack.

Figure 2. Repeatable voltage profiles under $100 \Omega$ external resistor by individual MFC units and serial and parallel connections.

Figure 3. Polarization curves (A) and power density curves (B) of the individual MFC units and stacks connected in series or in parallel.

Figure 4. Nyquist plots and equivalent circuit fit for individual MFC units and stacks connected in parallel and series. 
Table 1. Summary of the open circuit voltage, power density and equivalent circuit fit of experimental results for individual and stack MFC units.

\begin{tabular}{lccccccc}
\hline $\begin{array}{c}\text { Type } \\
\text { Connection }\end{array}$ & $\mathrm{E}_{\mathrm{MFC}}(\mathbf{O C V})$ & $\mathrm{P}_{\mathrm{s}, \max }\left(\mathbf{m W} \cdot \mathbf{m}^{-2}\right)$ & $\operatorname{Romh}(\Omega)$ & $\operatorname{Rct}(\Omega)$ & $\operatorname{Rd}(\Omega)$ & $\operatorname{Cdl}(\mathbf{F})$ & $\operatorname{Rint}(\Omega) *$ \\
\hline MFC 1 & $560 \pm 1.32$ & $80 \pm 6.23$ & $8.81 \pm 0.21$ & $195.90 \pm 15.04$ & $644.70 \pm 31.89$ & $5.256 \mathrm{E}-06$ & $849.41 \pm 1.32$ \\
MFC 2 & $581 \pm 1.54$ & $158 \pm 10.01$ & $9.00 \pm 0.58$ & $88.63 \pm 1.45$ & $102.61 \pm 8.66$ & $2.926 \mathrm{E}-04$ & $200.24 \pm 0.70$ \\
MFC 3 & $577 \pm 0.80$ & $126 \pm 2.42$ & $10.00 \pm 1.15$ & $150.30 \pm 19.55$ & $299.47 \pm 14.59$ & $2.372 \mathrm{E}-05$ & $459.77 \pm 1.02$ \\
MFC PARALLEL & $567 \pm 2.11$ & $142 \pm 6.71$ & $3.25 \pm 1.01$ & $114.30 \pm 22.59$ & $277.51 \pm 21.60$ & $5.993 \mathrm{E}-04$ & $395.06 \pm 1.16$ \\
MFC SERIES & $1100 \pm 9.87$ & $97.5 \pm 7.5$ & $30.00 \pm 2.94$ & $80.18 \pm 8.26$ & $435.08 \pm 41.00$ & $9.449 \mathrm{E}-05$ & $545.26 \pm 1.51$ \\
\hline
\end{tabular}

$\mathrm{P}_{\mathrm{S}-\mathrm{max}}$ : maximum power density

$\pm:$ standard deviation

*Internal resistance calculated from impedance analy sis 


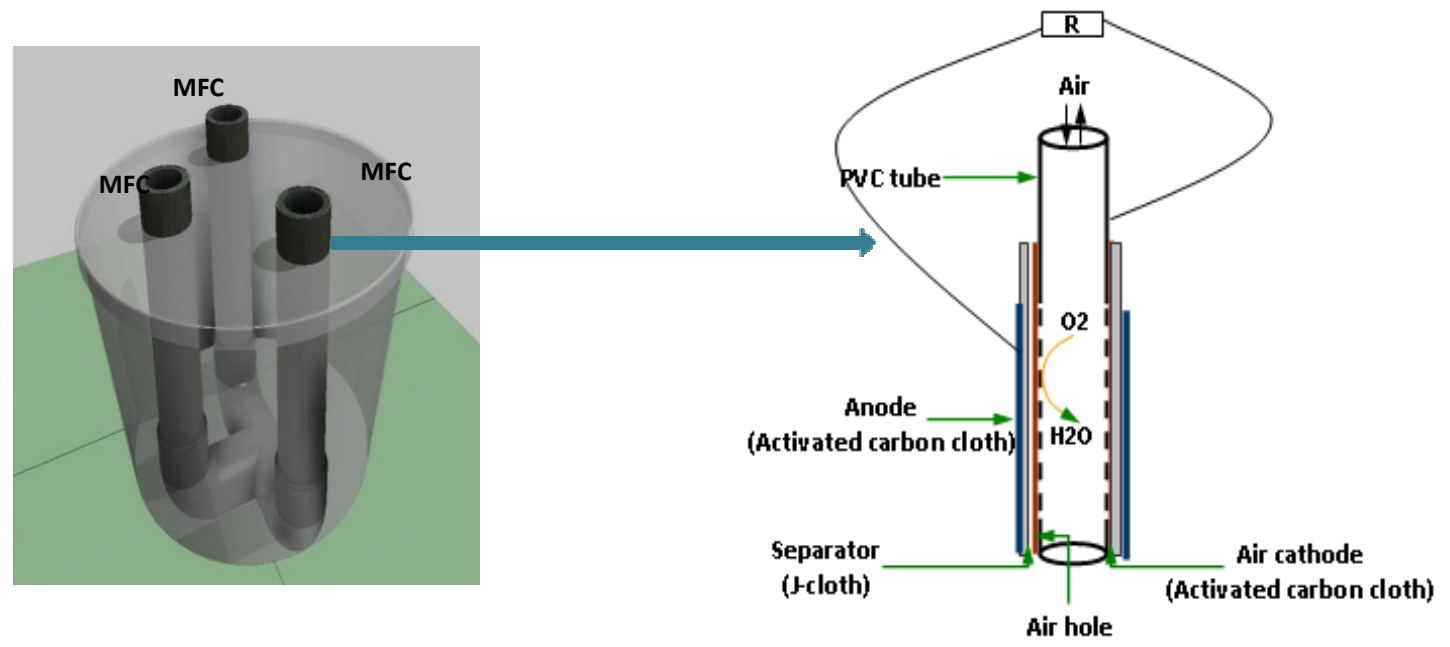

Figure 1. Schematic design and detailed structure of the pluggable microbial fuel cell stack. 


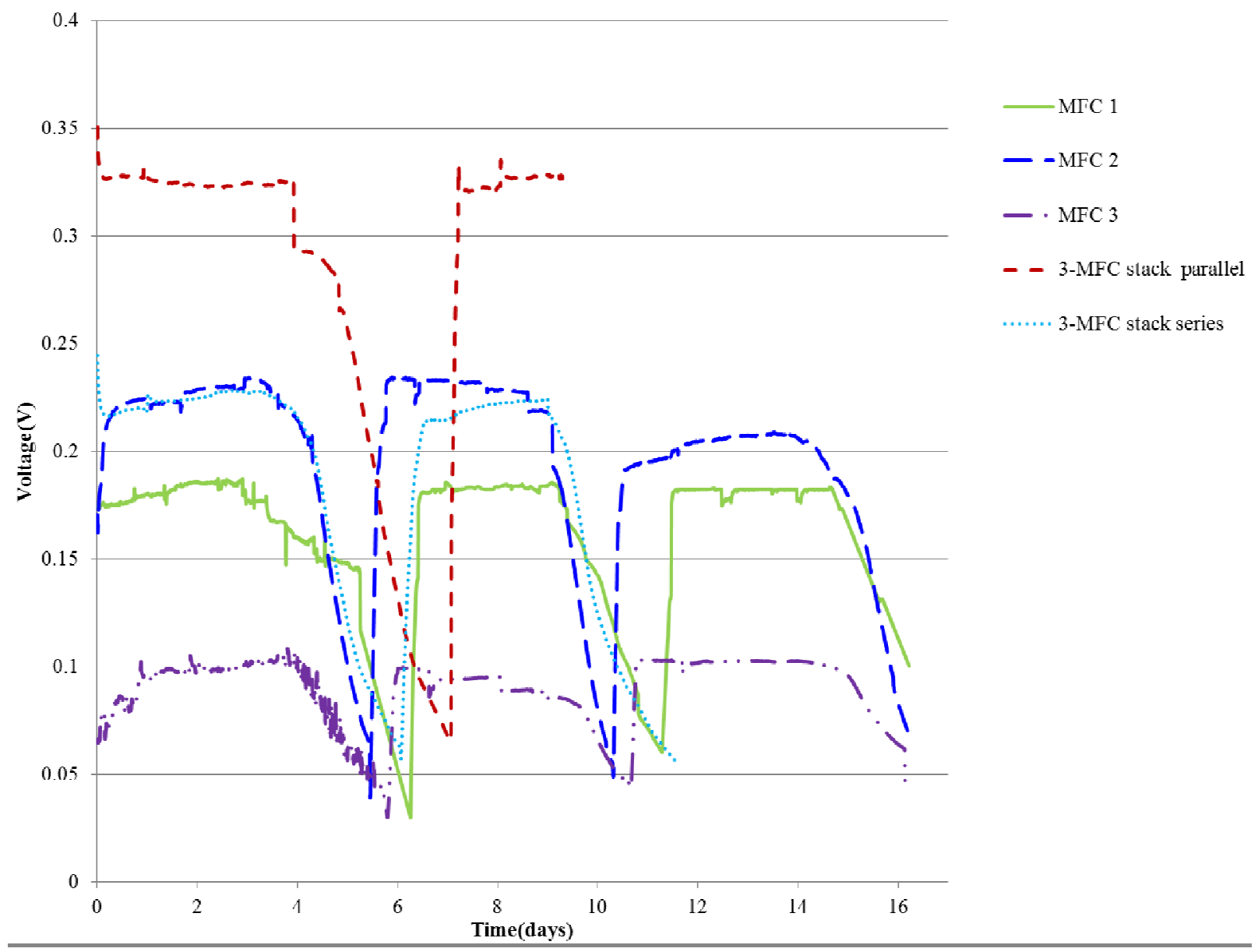

Figure 2. Repeatable voltage profiles under $100 \Omega$ external resistor by individual MFC units and serial and parallel connections. 


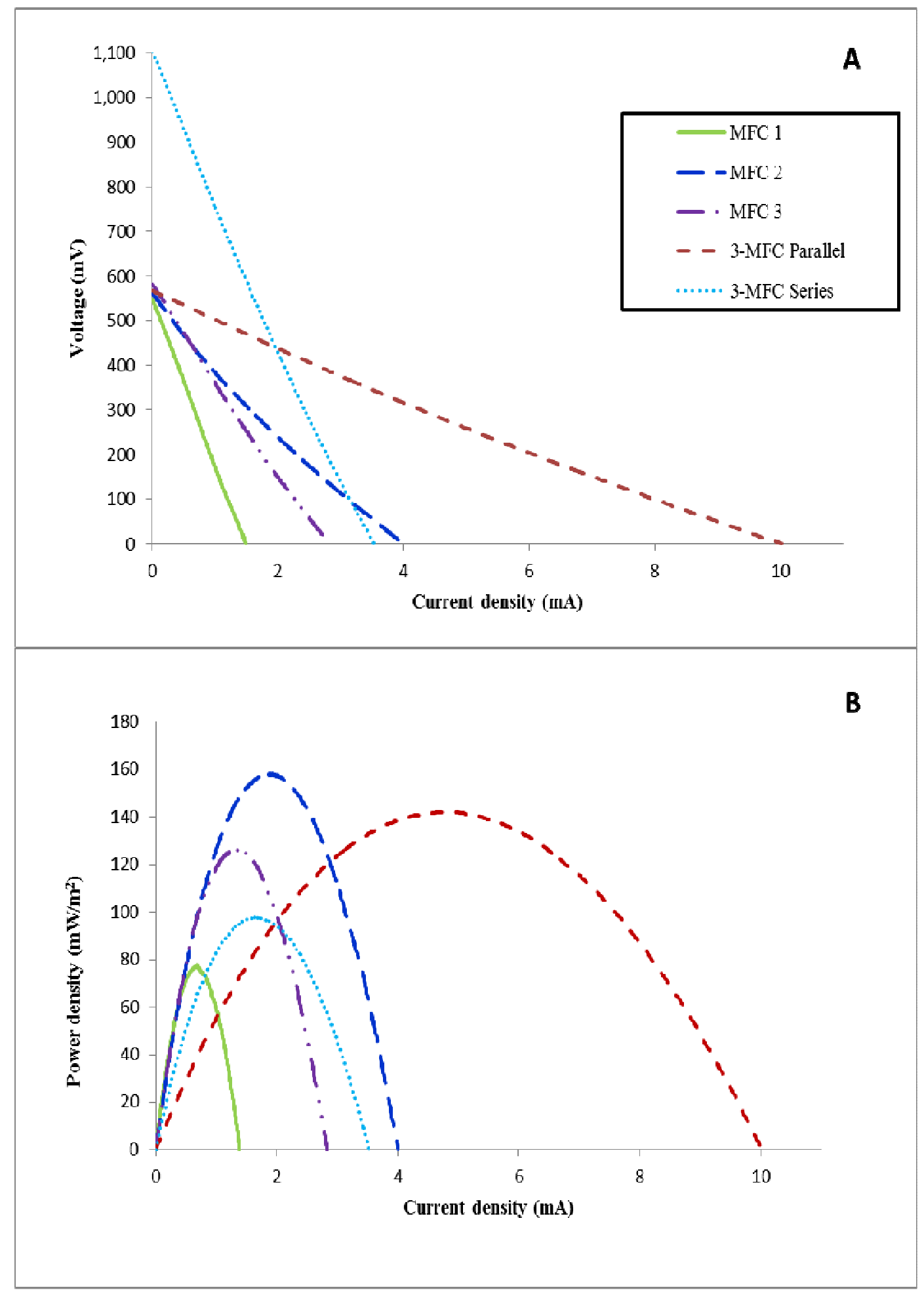

Figure 3. Polarization curves (A) and power density curves (B) of the individual MFC units and stacks connected in series or in parallel. 


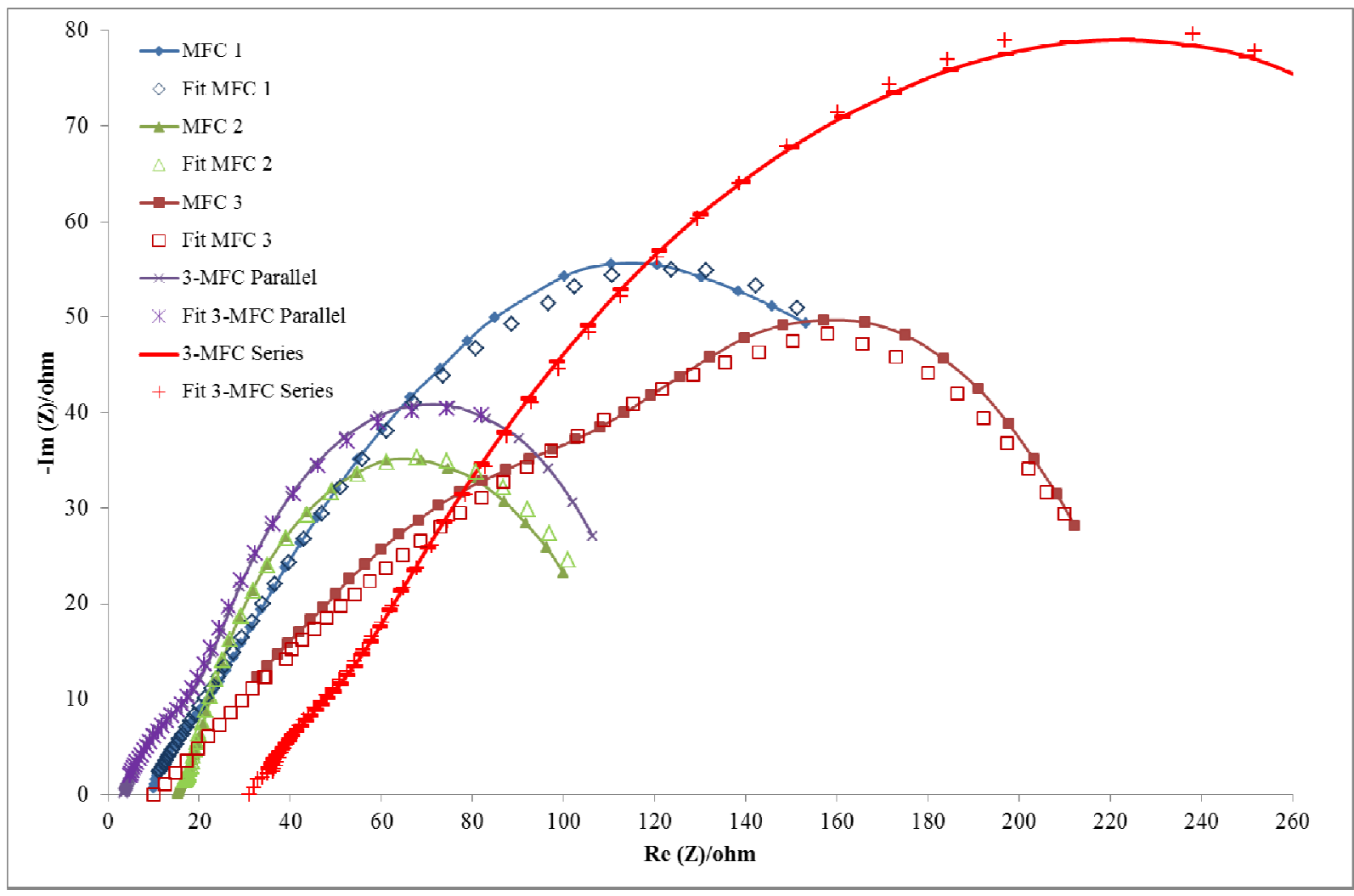

Figure 4. Nyquist plots and equivalent circuit fit for individual MFC units and stacks connected in parallel and series. 


\section{BITE_14422}

Table 1. Summary of the open circuit voltage, power density and equivalent circuit fit of experimental results for individual and stack MFC units.

\begin{tabular}{llllllll}
\hline $\begin{array}{c}\text { Type } \\
\text { Connection }\end{array}$ & $\mathrm{E}_{\mathrm{MFC}}(\mathrm{OCV})$ & $\mathrm{P}_{\mathrm{s}, \max }\left(\mathrm{mW} \cdot \mathrm{m}^{-2}\right)$ & $\mathrm{R}_{\mathrm{omh}}(\Omega)$ & $\mathrm{R}_{\mathrm{ct}}(\Omega)$ & $\mathrm{R}_{\mathrm{d}}(\Omega)$ & $\operatorname{Cdl}(\mathrm{F})$ & $\operatorname{Rint}(\Omega)$ \\
\hline MFC 1 & $560 \pm 1.32$ & $80 \pm 6.23$ & $8.81 \pm 0.21$ & $195.90 \pm 15.04$ & $644.7 \pm 31.89$ & $5.256 \mathrm{E}-06$ & $849.41 \pm 1.32$ \\
MFC 2 & $581 \pm 1.54$ & $158 \pm 10.01$ & $9.00 \pm 0.58$ & $88.63 \pm 1.45$ & $102.61 \pm 8.66$ & $2.926 \mathrm{E}-04$ & $200.24 \pm 0.70$ \\
MFC 3 & $577 \pm 0.80$ & $126 \pm 2.42$ & $10.00 \pm 1.15$ & $150.30 \pm 19.55$ & $299.47 \pm 14.59$ & $2.372 \mathrm{E}-05$ & $459.77 \pm 1.02$ \\
MFC PARALLEL & $567 \pm 2 . .11$ & $142 \pm 6.71$ & $3.25 \pm 1.01$ & $114.30 \pm 22.59$ & $277.51 \pm 21.60$ & $5.993 \mathrm{E}-04$ & $395.06 \pm 1.16$ \\
MFC SERIES & $1100 \pm 9.87$ & $97.5 \pm 7.5$ & $30.00 \pm 2.94$ & $80.18 \pm 8.26$ & $435.08 \pm 41.00$ & $9.449 \mathrm{E}-05$ & $545.26 \pm 1.51$ \\
\hline
\end{tabular}

$\mathrm{P}_{\mathrm{s}, \max }$ : maximum power density

\pm : standard deviation

Internal resistance calculated from impedance analysis 